\title{
Metallization of Porous Polyethylene Using a Wire-Arc Spray Process for Heat Transfer Applications
}

\author{
S. Devaraj ${ }^{1} \cdot$ A. McDonald ${ }^{2} \cdot$ S. Chandra ${ }^{1}$
}

Submitted: 28 August 2020/in revised form: 14 October 2020/Accepted: 27 October 2020/Published online: 3 January 2021

(C) ASM International 2021

\begin{abstract}
Metallization of polyethylene (PE) using thermal spray techniques has proved difficult due to its low melting point and softness. In this study, metallic coatings were applied on porous polyethylene substrates using a twin wire-arc spray process. Commercially available polyethylene sheets, $3 \mathrm{~mm}$ in thickness, were used as substrates. Copper $(\mathrm{Cu})$, aluminum $(\mathrm{Al})$, and zinc $(\mathrm{Zn})$ were successfully deposited on the porous polymer, without prior surface preparation, to form coatings with thickness of about $400 \mu \mathrm{m}$. Coating surface morphology and crosssections were examined using a scanning electron microscope. Individual metal splats on the porous and non-porous substrates were observed to study the differences in the bonding mechanisms. The adhesion strength and electrical resistivity of the coatings on porous PE were evaluated. It was found that the bond strength of all three metallic coatings was found to be higher than the ultimate fracture strength of the porous. These results suggest that porosity in the polymer helps to overcome the challenges of metallizing polyethylene and provides a significant reduction in the weight of the polymer. Therefore, all these properties
\end{abstract}

This article is an invited paper selected from abstracts submitted for the 2020 International Thermal Spray Conference, ITSC2020, that was to be held from June 10-12, 2020, in Vienna, Austria. The conference was cancelled due to the coronavirus (COVID-19) pandemic. The paper has been expanded from the planned presentation.)

S. Devaraj

dsuchan7696@gmail.com

1 Department of Mechanical and Industrial Engineering, University of Toronto, Toronto, ON M5S 3G8, Canada

2 Department of Mechanical Engineering, University of Alberta, Edmonton, AB T6G 1H9, Canada aided in fabricating an extremely lightweight, composite material with potential use in thermal management applications.

Keywords polymer metallization $\cdot$ porous substrate $\cdot$ splat impact · wire-arc spraying

\section{Introduction}

Polyethylene, a thermoplastic material generally known for its excellent impact resistance and low specific weight, is widely used as a packaging material to make carry bags and water pipes and in medical applications [1]. Polyethylene, and similar polymers, also have potential applications in power electronics where they can be used to make lightweight heatsinks or heat exchangers that are widely used to cool electronic equipment [2, 3]. The combination of low material cost, processing ease, low density and high electrical resistivity makes polymeric heatsinks and heat exchangers economical substitutes for metallic materials. However, for such applications, the thermally non-conductive polymer needs to be engineered to make it thermally conductive [4]. One technique is to mix high thermal conductivity materials such as metals or carbon with the polymer during fabrication [5]. Another method is metallization, where a conductive metal layer is applied on top of the plastic substrate. Coating methods include vacuum metallization (physical vapor deposition and chemical vapor deposition), plating (electroless and electroplating) and thermal spray coating processes [6].

Thermal spray deposition is a simple, well-developed and flexible surface engineering technique widely used to develop metallic and ceramic coatings on metallic substrates [7]. Thermal spraying processes generally have a 
much higher deposition rate than electroplating and vacuum metallization and can produce thicker metal layers on polymeric substrates [8]. Spraying allows for deposition of metal coatings on selected areas of component substrates, which is useful when working with complex shaped parts. However, it is a high-temperature process and involves impingement of molten particles, with very high velocity, on the coating substrate [9]. Therefore, research involving thermal spray metallization of polymers, especially soft and low melting temperature plastics like polyethylene, polyurethane (PU), and polyvinyl chloride is limited.

The first lightweight polymeric heat exchangers were made in 1965 [10]. In order to improve the heat transfer performance of polymeric heat exchangers, researchers used thermally conductive fillers inside these polymers to enhance the overall thermal conductivity of the composite heat exchangers [11]. Such advancements produced many practical applications of polymer composite materials such as solar water heating [12], automotive radiators [13], water desalination [14], condensing boilers [15], and electronics cooling [16]. However, the challenges involved in achieving a uniform filler dispersion in the polymers largely limit their applications. Tessema et al. [17] discussed the effect of dispersion on the thermal conductivity of the overall composites.

Chen et al. [3] fabricated a lightweight heatsink consisting of an acrylonitrile butadiene styrene core and a thin zinc coating layer on the polymer surface, which was deposited using a wire-arc thermal spray process. Fabrication of acrylonitrile butadiene styrene requires a similar moulding temperature as polyethylene. The zinc coating provided the desired heat conduction path, and the polymer acted as a lightweight structural support material. Materials such as aluminum and copper are usually used to fabricate heat sinks because of their high thermal conductivity and reasonably low coefficient of thermal expansion. The higher melting temperatures of aluminum and copper make them difficult to deposit by using thermal spray systems. To protect the polymer surface from thermal damage during spraying and to promote adhesion, Ashrafizadeh et al. [18] co-cured polyurethane with Al-12Si particles on the surface before flame spraying with Al-12Si powders. This approach minimized direct contact of the high-temperature spray particles with the substrate during impact.

Cold spray, which has lower operating temperatures, has also been used to metallize plastics, but the significantly higher impact force of particles in this process can damage the substrate and prevent adhesion [19-21]. Che et al. [20] cold-sprayed $\mathrm{Cu}$ particles onto carbon fiber-reinforced polymer (CFRP) and observed substrate erosion caused by impinging metal particles, which was worsened by the brittleness of the substrate. In another study, cold spray deposition of copper onto high-density polyethylene
(HDPE) leads to embedment of metal particles into the substrate without forming a continuous coating [21].

In some cases, the polymer substrate surfaces are modified prior to thermal spray deposition of the coating to enhance the coating bond strength. The most common techniques employed on metallic and ceramic substrates include grit blasting and pre-heating the substrates prior to spraying [22]. While grit blasting enhances mechanical interlocking of the coating on the substrate, pre-heating the metallic substrates helps remove any volatile absorbents on the surface. However, the soft and heat-sensitive nature of some of the polymeric materials limits the use of such surface preparation techniques. Rezzoug et al. [23] cocured an aluminum mesh in a CFRP substrate to achieve a significant improvement in the bond strength of $\mathrm{Zn}$ coating on these substrates. Huang et al. [24] deposited a zinc bond-coat on a polymer matrix composite prior to plasma spraying the final yttria-stabilized zirconia (YSZ) coating to protect the plastic surface from high particle temperatures. Such techniques, however, introduce an additional step in the coating process.

The objective of this study was to deposit dense metallic coatings of zinc, aluminum and copper on porous polyethylene substrates using twin wire-arc spraying. While previously published works sought to surface preparation methods prior to coating, in the present paper, no surface modification was required to achieve good adhesion. The adhesion strength of the metal coatings and their electrical resistivity were measured by using standard pull tests and four-wire sensing method, respectively. The coating-porous polymer interface was examined using scanning electron microscope (SEM) images. Individual metal splats on the polymeric surface were also observed using the SEM to provide insight into the interaction of molten metal particles with the porous polymer during impact.

\section{Experimental Methods}

\section{Wire-Arc Spraying}

An electric twin-wire arc spray system (Thermion, Silverdale, Washington, USA, P/N: 57456), mounted on a robot arm, was used to melt and spray high purity zinc (Oerlikon Metco, Westbury, NY, USA, DSMTS-0010.6), aluminum (Oerlikon Metco, Westbury, NY, USA, DSMTS-0003.10) and copper wires (Oerlikon Metro, Westbury, NY, USA, DSMTS-0009.7) onto the porous polyethylene substrates. The average sizes of zinc, aluminum, and copper spray particles were determined by spraying the metal particles into a water bath. The particles were then allowed to dry under natural convection. A Malvern Mastersizer X laser analyser (Malvern 
Instruments Ltd., Malvern, Worcestershire, UK, P/N: 2000) was used to measure the particle size distribution of zinc, aluminum and copper particles.

All spray parameters for the three metals were kept constant except the input arc voltage, which was $28 \mathrm{~V}$ for zinc and $32 \mathrm{~V}$ for aluminum and copper. Dry air was chosen as the atomizing gas, and the gas pressure was fixed at $690 \mathrm{kPa}$. A nozzle stand-off distance of $152 \mathrm{~mm}$ was used. All samples used in this work were cooled using compressed air during spraying. The robotic arm, which holds the spray nozzle, was programmed to move at a speed of $1000 \mathrm{~mm} / \mathrm{min}$ in a serpentine pattern consisting of parallel passes spaced $5 \mathrm{~mm}$ apart. Identical process parameters were used for single particle impact experiments.

\section{Polymeric Substrate Surfaces}

All porous polymeric samples (Scientific Commodities, Inc., Lake Havasu City, AZ, USA, P/N: BB2062-35) used in this work were manufactured by free sintering of ultrahigh molecular weight polyethylene powders. The porosity and density of the samples stated by the manufacturer were approximately $35-40 \%$ (void volume percentage) and $0.58 \mathrm{~g} / \mathrm{cm}^{3}$, respectively. The porous substrates were hydrophilic, and their mean pore size was about $70 \mu \mathrm{m}$. The non-porous polyethylene substrates (McMaster-Carr, Sante Fe Springs, CA, USA, P/N: 8752K111) used in this work had a density of about $0.9 \mathrm{~g} / \mathrm{cm}^{3}$, about 1.5 times higher than that of the porous polymeric substrates. In preparation for spraying of thick coatings, all samples were cut to $50 \mathrm{~mm} \times 50 \mathrm{~mm}$, with a thickness of $3 \mathrm{~mm}$. For the single splat study, sample dimensions of $25 \mathrm{~mm} \times 25$ $\mathrm{mm} \times 3 \mathrm{~mm}$ were used. No surface preparation was done before coating, and samples on which metal was deposited were as received from the manufacturer. The surface roughness of the samples was measured before coating deposition using a skid-reference profilometer (Precision Devices Inc., Michigan, USA, P/N: PDA-400ao). A total of at least 10 measurements were taken.

\section{Experimental Assembly}

A schematic of the experimental apparatus used to capture single splats is shown in Fig. 1. The polymer samples were mounted on a steel support and positioned in such a way that the axis of the metal spray impacted the center of the substrate during spraying. A steel plate in which a $1 \mathrm{~mm}$ diameter hole was drilled was placed between the spray and the polymer substrate. As the wire-arc spray moved over the substrate, only a few droplets passed through the orifice so that after a single pass of the spray individual metal splats could be identified. To deposit a complete coating on the substrate, the protective barrier was removed from the experimental assembly.

\section{Coating Characterization}

The coated samples were cut and cold-mounted in an epoxy resin (Buehler, EpoxyCure 2 Resin, Illinois, USA, $\mathrm{P} / \mathrm{N}$ : 203430064) for microstructural examination. The sections were then polished using 240, 320, 400, 600, 800, and 1200 grit silicon carbide paper (Buehler, CarbiMet ${ }^{\mathrm{TM}}$ SiC Abrasive Paper, Lake Bluff, IL, USA) and mirrorpolished using 9,3 , and $0.01 \mu \mathrm{m}$ diamond slurry suspension (Buehler, Metadi ${ }^{\circledR}$ Diamond Suspension - water base, Lake Bluff, IL, USA). The cross sections of the coatings were analyzed using a scanning electron microscope (SEM) (Hitachi Tabletop, country, P/N: TM 3000) at low voltage mode $(5 \mathrm{~V})$ to avoid charging of the non-conducting polymer samples. Additionally, the surface topographies of single splats and bare polymer substrates were examined using an SEM to have a good understanding of the interaction of molten metal particles with porous polymer substrates. The mean splat size and circularity of the individual metallic splats were calculated using image processing software, ImageJ-NIH.

\section{Adhesion Strength}

Pull tests (PosiTest ${ }^{\mathrm{TM}}$ AT-M Manual Tester, DeFelsko, St. Catherines, ON, Canada, P/N: ATM20) were done on coating samples with dimensions of $50 \mathrm{~mm} \times 50 \mathrm{~mm}$ to determine the metal-polymer coating bond strength as per ASTM standard D4541. The bond strength of the coatings deposited on both 3 and $6 \mathrm{~mm}$ thick samples was compared. A total of 5 samples of each zinc, aluminum, and copper coatings were tested. A standard ATM20 Al pull stub of $20 \mathrm{~mm}$ diameter was bonded to the coated samples using an epoxy adhesive (Devcon No. 19770 'plastic steel' two-part epoxy, Aurora, Ohio, USA, P/N: 19770). Once the epoxy hardened, the pull test was done using loads of 0.5 $20 \mathrm{MPa}$.

\section{Electrical Resistance Measurement}

The electrical resistance of the deposited coatings was measured using the four-wire sensing method with a 5.5digit precision multimeter (Fluke 8808A, Fluke Electronics Canada LP, Mississauga, ON, Canada). Ashrafizadeh et al. [25] conducted four-wire sensing experiments to evaluate the electrical resistivity of flame-sprayed aluminum with 12 wt.\% silicon (Al-12Si) on polyurethane substrates. In their study, two thin copper sheets were attached to the coating surface using silver epoxy to provide an electrically conductive path. In the present study, four holes were 


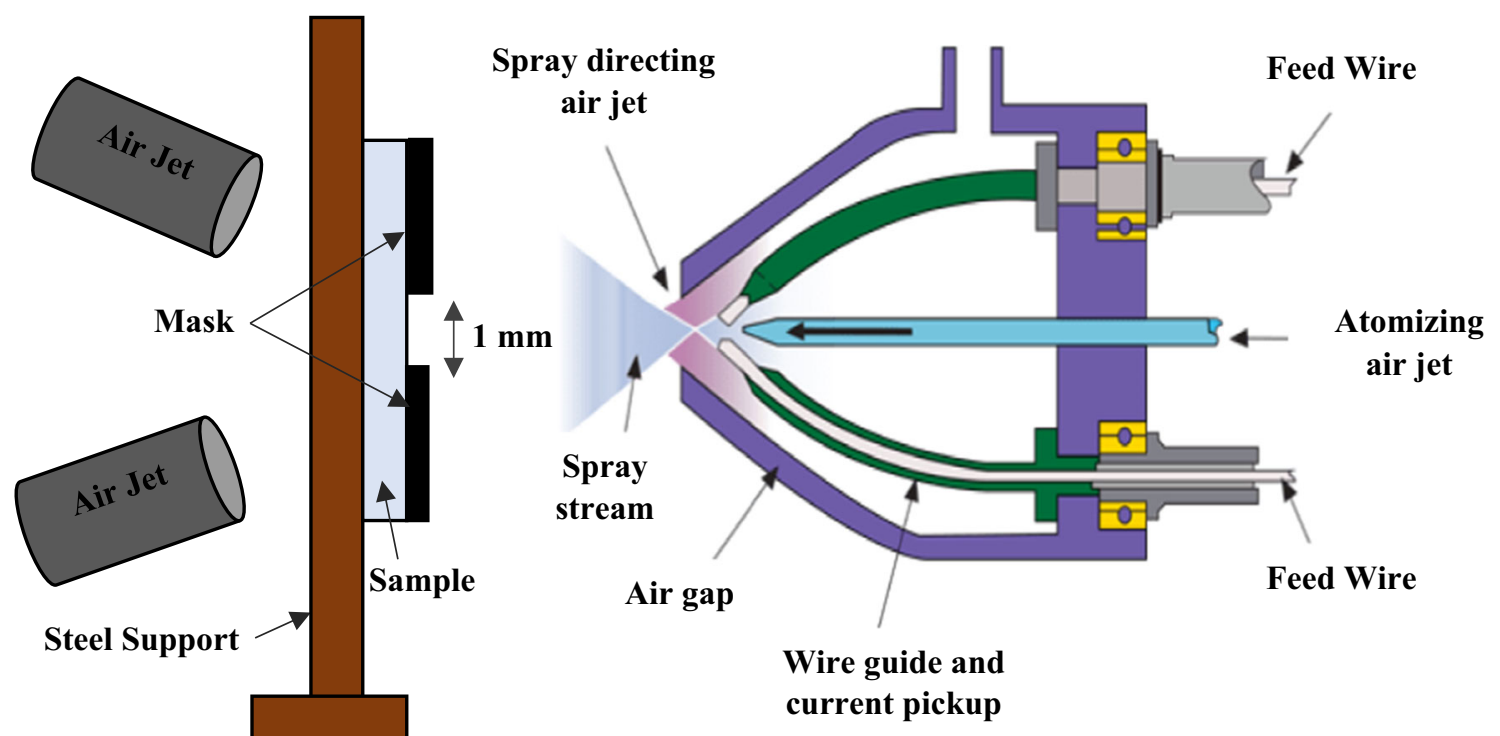

Fig. 1 Schematic diagram of single splat experimental apparatus

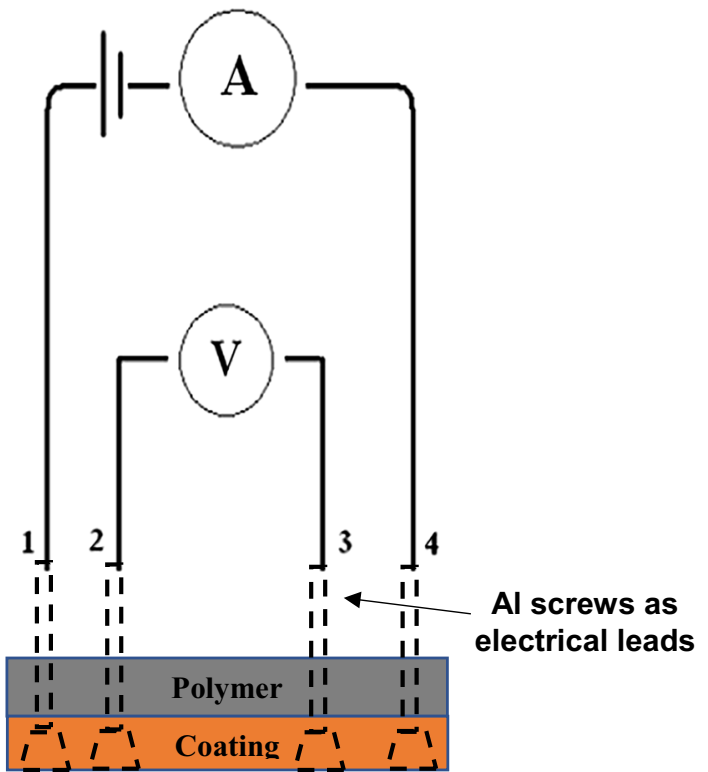

Fig. 2 Experimental schematic of four-wire sensing assembly for electrical resistivity measurement

drilled in the samples to insert aluminum bolts as shown in Fig. 2. The aluminum bolts acted as electrodes. The wires connecting the multimeter were attached to the aluminum bolts using alligator clips.

\section{Results and Discussion}

\section{Size Distribution of Spray Particles}

Figure 3 shows SEM images of spray particles of aluminum (Fig. 3a), zinc (Fig. 3b), and copper (Fig. 3c). Aluminum and zinc particles were observed to be more irregular than copper particles, which were approximately spherical. The mean particle sizes $\left(d_{50}\right)$ of zinc, aluminum and copper were measured to be $61 \pm 11 \mu \mathrm{m}, 78 \pm 13 \mu \mathrm{m}$ and $40 \pm 6 \mu \mathrm{m}$, respectively. The mean particle diameter of aluminum and zinc was within $10 \mu \mathrm{m}$ of the mean substrate pore size $(\sim 70 \mu \mathrm{m})$, while copper particles were about $30 \mu \mathrm{m}$ smaller.

\section{Substrate Roughness}

The polymers received from the manufacturer had mean surface roughness $\left(R_{\mathrm{a}}\right)$ values of approximately $3.4 \pm 0.2$ $\mu \mathrm{m}(n=10)$. Sintering of the polymer powders during manufacture resulted in an uneven surface topography which can be seen in the SEM image of the bare polyethylene surface (Fig. 4). The surface roughness of porous polyethylene was significantly higher than that of the nonporous polyethylene substrates $\left(R_{\mathrm{a}}=1.5 \pm 0.05 \mu \mathrm{m}\right.$ for $n=10$ ), even after they were roughened by grit blasting [26]. 
Fig. 3 SEM images of particles of (a) zinc (mean particle diameter $\left.d_{50}=61 \mu \mathrm{m}\right)$, (b) aluminum $\left(d_{50}=78 \mu \mathrm{m}\right)$, and (c) copper $\left(d_{50}=40 \mu \mathrm{m}\right)$ captured by spraying into a water bath

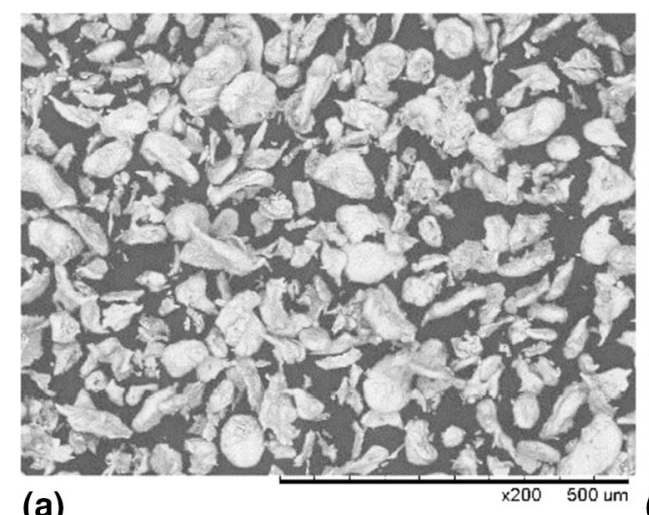

(a)

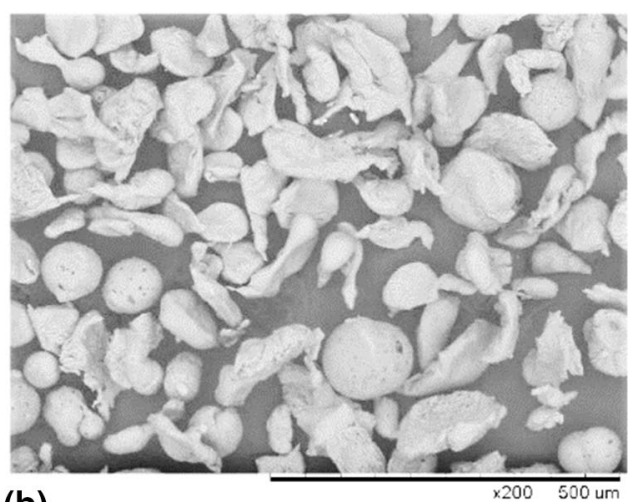

(b)

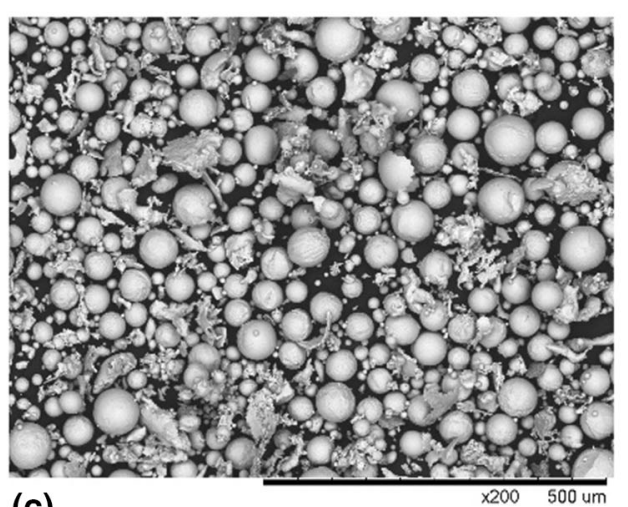

(c)
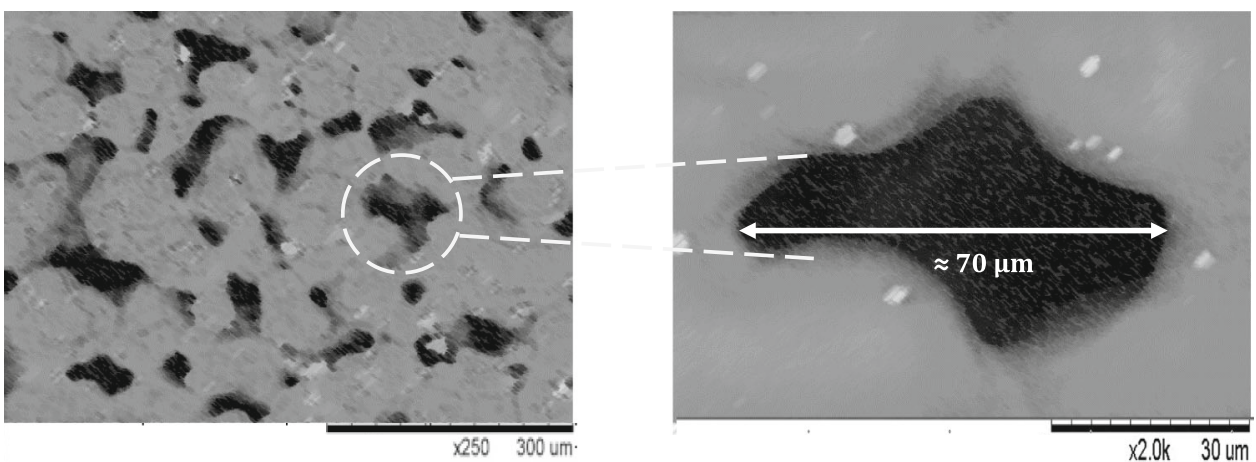

Fig. 4 SEM image of asreceived porous polyethylene

\section{Coating Cross-Section Characterization}

Zinc coatings, at $260 \pm 20 \mu \mathrm{m}$ thick $(n=5)$, have been previously deposited on non-porous polyethylene substrates using a wire-arc spray; however, aluminum and copper particles did not adhere to the polymer due to their high melting point [27]. Grit blasting the non-porous substrates prior to thermal spraying did not improve adhesion of copper and aluminum coatings. However, all three metals adhered well to the porous polymer and formed thick coatings.

The interface between the metallic coating and porous polymer substrate is shown in Fig. 5. An average coating thickness of about $400 \pm 20 \mu \mathrm{m}(n=5)$ was achieved after 9-10 passes of the spray torch for all three metals, namely zinc (Fig 5a), aluminum (Fig. 5b) and copper (Fig. 5c and d). Coatings were observed to penetrate deep into the pores present on the surface, and the penetration depth exceeded $50 \mu \mathrm{m}$ (measured from the surface) in certain regions, thus providing excellent mechanical anchorage. In portions of the copper coatings (highlighted in Fig. 5c and d), metal fingers penetrating adjacent pores in the substrate almost encapsulated the polyethylene substrate. The smaller size of copper particles $(\sim 40 \mu \mathrm{m})$ permitted deep penetration into pores, which was not observed in aluminum and zinc coatings where the particle size was larger. The deeper penetration of copper particles was also promoted by the melting of the polymer surface due to the comparatively high melting temperature of copper. Furthermore, the momentum of copper particles 
Fig. 5 Cross-sectional view of metallic coatings, (a) zinc coating, (b) aluminum coating, (c) and (d) copper coating on porous polyethylene substrates. Areas where the coatings almost encapsulated the polyethylene substrates are outlined in (c) and (d)

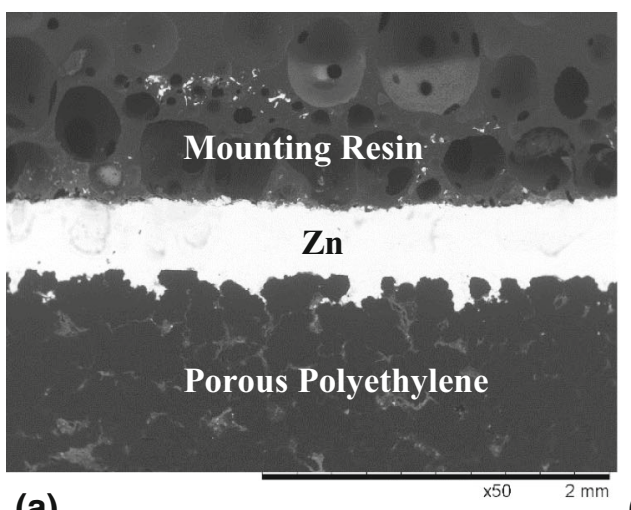

(a)

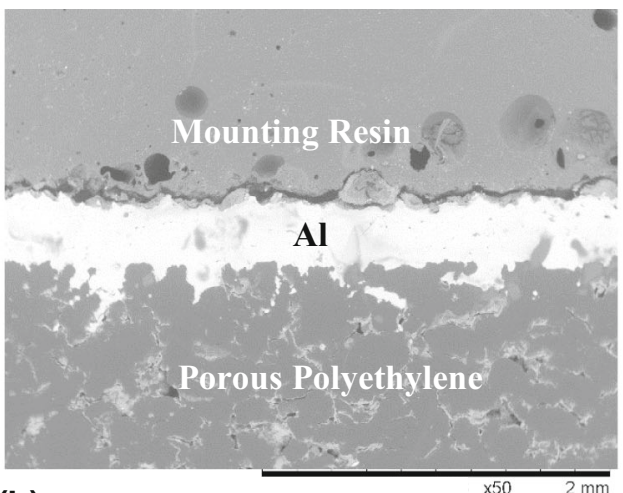

(b)
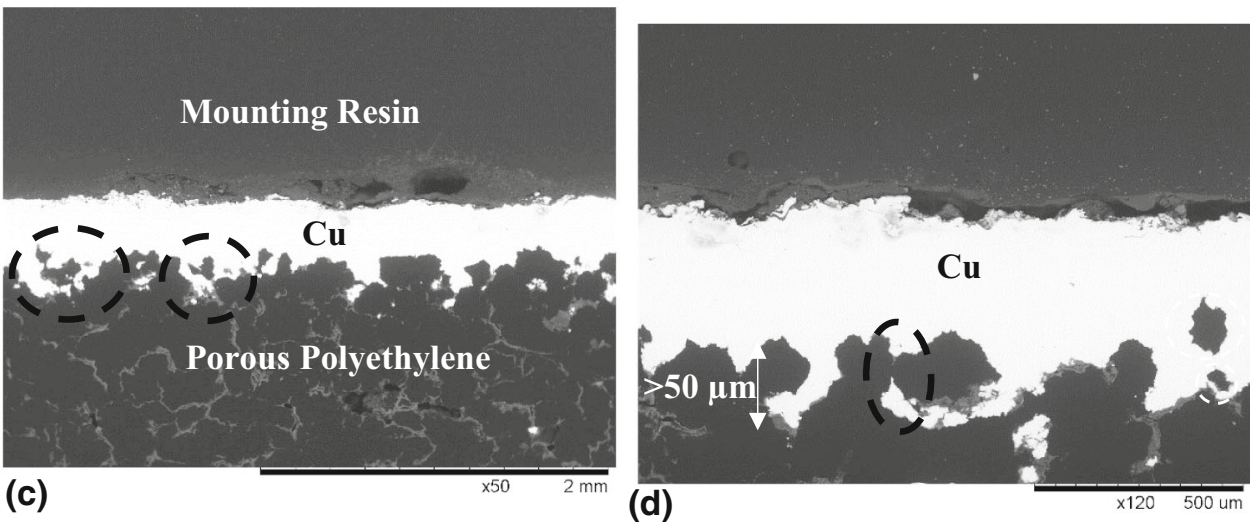

may also be higher due to the higher density of copper $\left(8960 \mathrm{~kg} / \mathrm{m}^{3}\right.$, compared to $2700 \mathrm{~kg} / \mathrm{m}^{3}$ for aluminum and $7140 \mathrm{~kg} / \mathrm{m}^{3}$ for zinc). The porous substrates promote a strong mechanical bond with the metal coatings thereby eliminating any requirement for substrate preparation prior to thermal spraying.

\section{Single Splat Characterization}

Figure 6 shows single splats of zinc (Fig. 6a), aluminum (Fig. 6b) and copper (Fig. 6c) splats on a non-porous polyethylene surface. The zinc and aluminum splats had flattened out and spread on the surface. Long fingers stretched out of the periphery of the zinc splat. Small satellite droplets were visible, which may be due to breakup of such fingers. The copper splat was much more spherical, indicating that it took longer to solidify so that surface tension forces had more time to pull the edges of the splat back.

Figure 7 shows SEM images of individual splats of zinc (Fig. 7a), aluminum (Fig. 7b) and copper (Fig. 7c) deposited on the porous substrates. Splats of zinc and aluminum were flattened out and had irregular shapes. They also appeared to be located mostly on the exterior of the substrate. Copper splats were more spherical and had penetrated deeper into pores. Zinc and aluminum spray droplets had mean diameter of about $60 \mu \mathrm{m}$ and $80 \mu \mathrm{m}$, while copper drops were smaller, about $40 \mu \mathrm{m}$ in diameter (see Fig. 3), making them more likely to penetrate into surface pores that were on average $70 \mu \mathrm{m}$ wide (see Fig. 4). Penetration into pores enhances coating bond strength by providing strong mechanical interlocking, which when coating impervious substrates is usually achieved by grit blasting them prior to thermal spraying [28].

Splat morphology was quantified by measuring the splat diameter $(D)$ and circularity $(C)$ as defined by:

$D=2 \sqrt{\frac{A}{\pi}}$
$C=\frac{4 \pi A}{P^{2}}$,

where $P$ and $A$ are the perimeter and surface area of the splat, respectively [29]. Measurements were carried out on 20-30 splats selected from each test sample. Separation lines were drawn manually around each splat and values of $P$ and $A$ determined using Image J software.

Figure 8 shows average values of splat diameters on both porous and non-porous substrates, compared with the initial particle diameter. For zinc, splat diameters on the non-porous surface were approximately 1.5 times the initial particle diameter, indicating that molten droplets impacted and spread without too much fragmentation. On the porous 
Fig. 6 Individual metal splats of (a) zinc, (b) aluminum and (c) copper sprayed on nonporous polyethylene

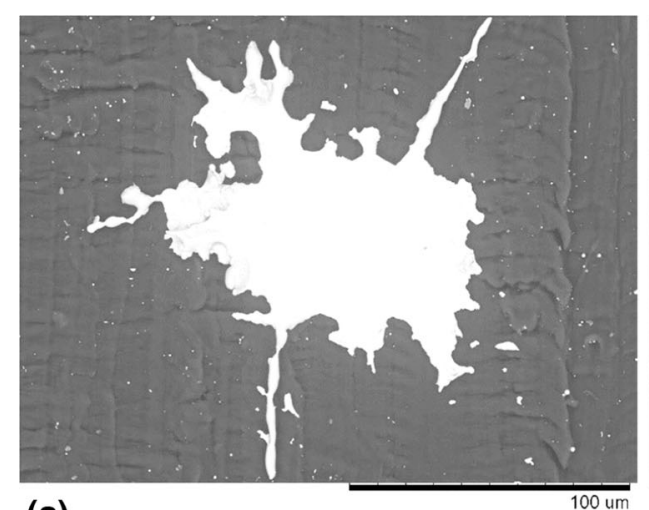

(a)

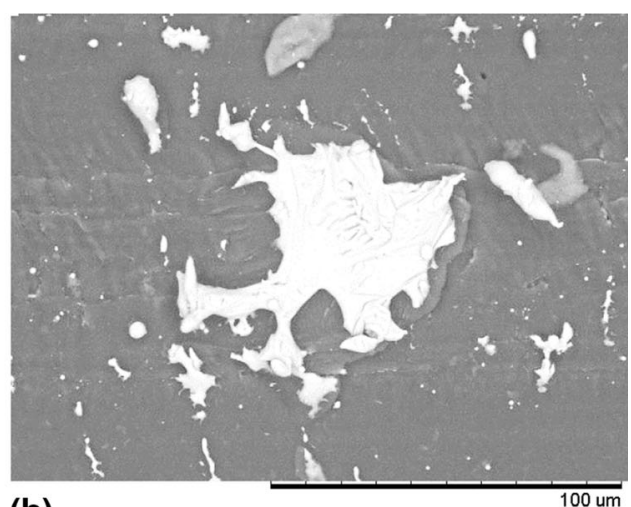

(b)

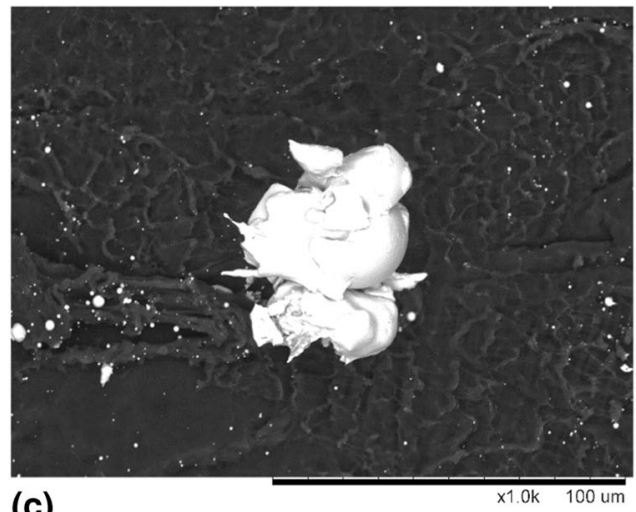

(c)

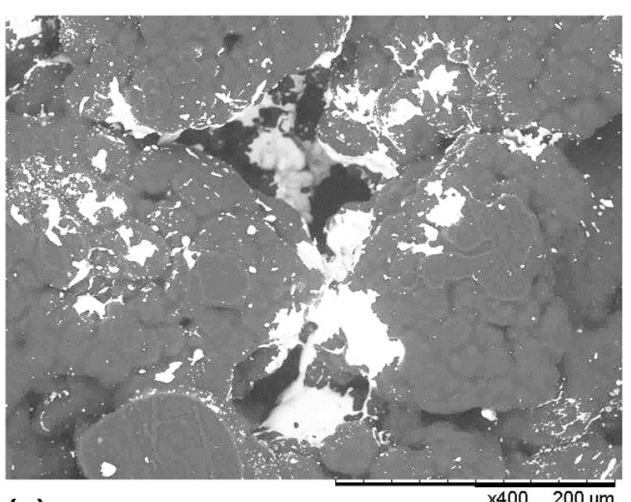

(a)

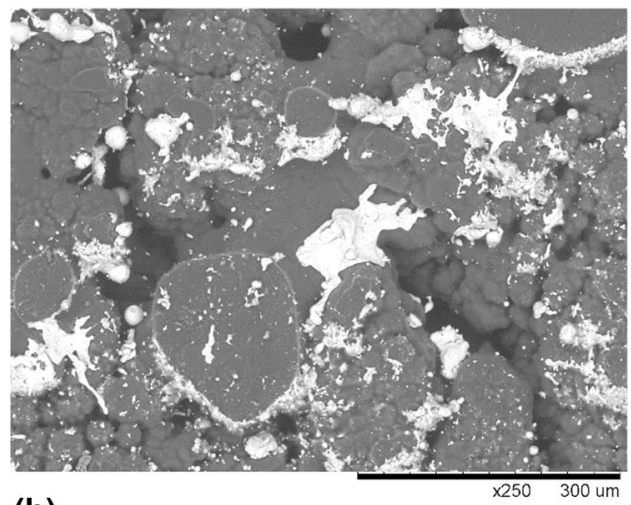

(b) splats of (a) zinc, (b) aluminum and (c) copper sprayed on porous polyethylene substrates

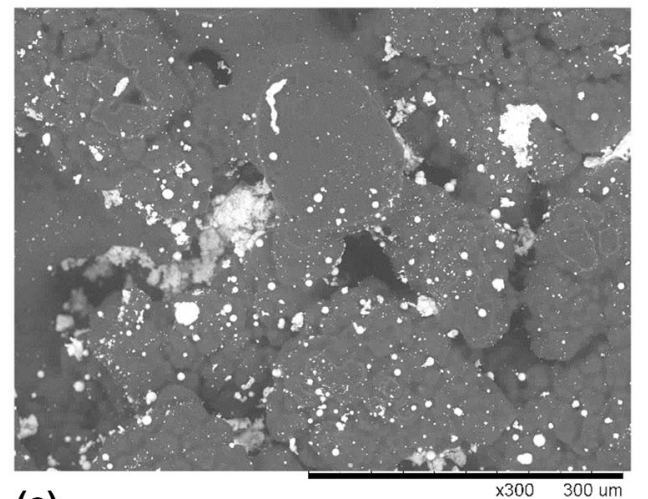

(c) 


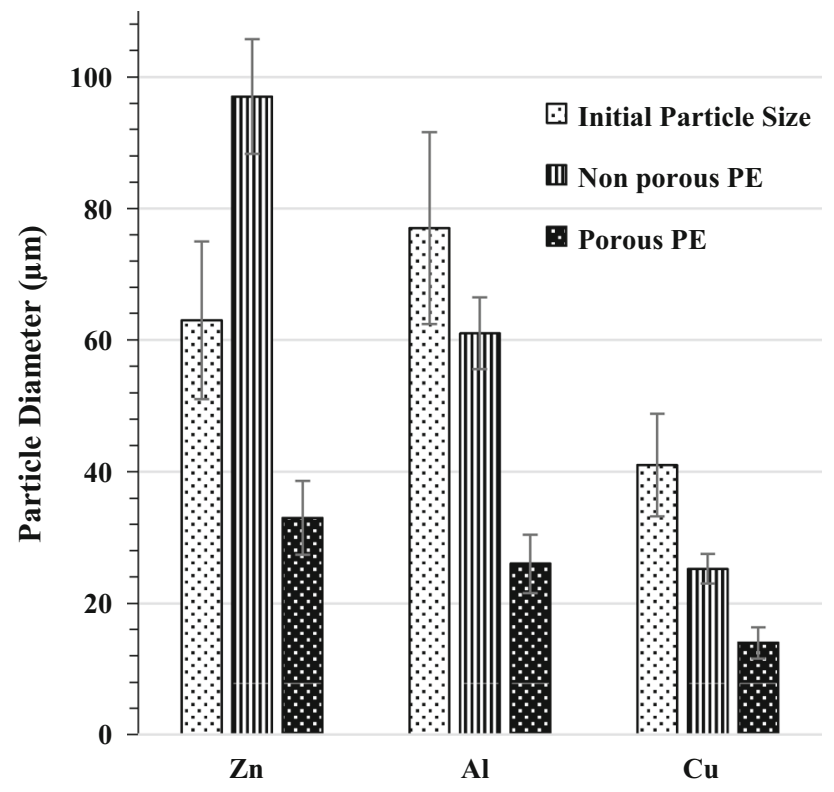

Fig. 8 Initial mean spray particle size and mean splat size of zinc, aluminum and copper

surface, zinc, aluminum, and copper splat diameters were less than half the diameter of the initial particles, suggesting that splats had fragmented during impact. This was possibly due to the high surface roughness of the substrate triggering splashing. McDonald et al. [30] showed that increasing the surface roughness of the coating substrate promoted splat splashing, restricted splat spreading, and resulted in splats with irregular morphologies.

Copper particles had splats that were smaller than the initial particles, on both the porous and non-porous surfaces. One reason is that on the porous surface they were more likely to land inside pores where they had less space to expand, which restricted splat spreading. This may also be due to the higher melting point of copper $\left(1085{ }^{\circ} \mathrm{C}\right.$, compared to $660{ }^{\circ} \mathrm{C}$ for aluminum and $420{ }^{\circ} \mathrm{C}$ for zinc), which would reduce the time taken for splat solidification and enhance splat fragmentation into smaller spherical droplets. Additionally, the higher melting temperature of $\mathrm{Cu}$ particles locally melted and softened the surface on impact which in turn lowered the resistance of the substrate to deformation on impact. All these factors contributed to the limited flattening of the copper particles on the PE substrate.

Figure 9 shows measured values of average circularity for splats on both non-porous and porous surfaces. Zinc splats had low circularity on both surfaces because of the presence of long fingers around the splat (see Fig. 6a). Aluminum spats had higher circularity on the non-porous surface, but lower on the porous one, which was due to break-up of splats and formation of fingers along surface crevices (see Fig. 7b). Copper splats had the highest value

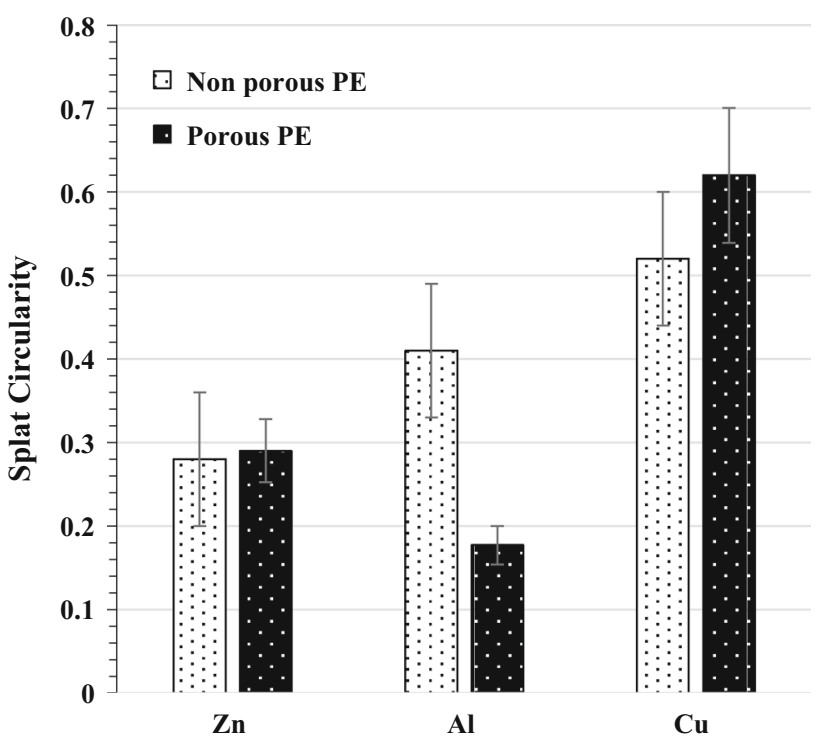

Fig. 9 Circularity of zinc, aluminum and copper splats formed on porous and non-porous polyethylene substrates

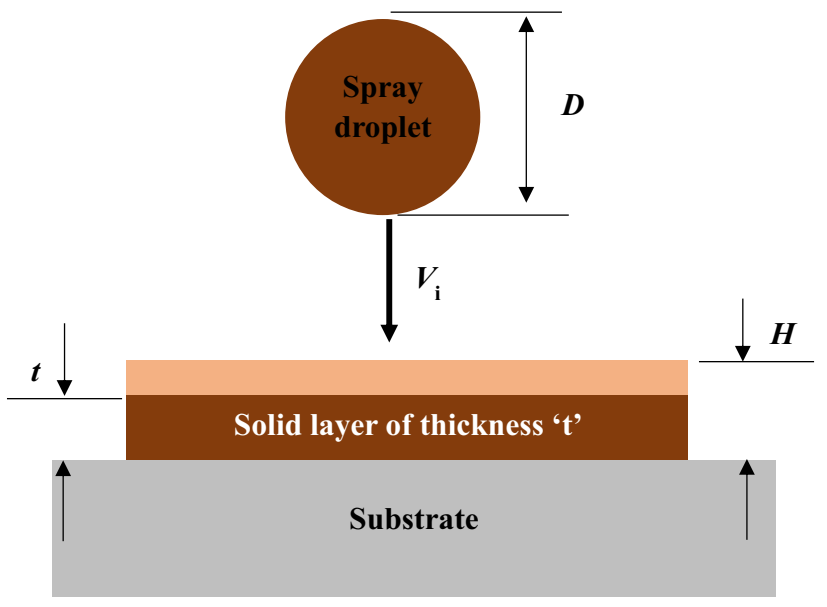

Fig. 10 Idealized splat formation on substrate

of circularity, and the value was higher on the porous surface because the splats were not flattened but appeared spherical (see Fig. 6c). On the porous surface, there was noticeable fragmentation, and the smaller satellite droplets were largely spherical (see Fig. 7c).

The effect of solidification of splat spread and fragmentation can be gauged by using the solidification parameter $(S P)$, which was defined by Dhiman et al. [31] as $S P=t / H$, where $t$ is thickness of the solid layer formed in the splat when it reached the maximum spread diameter (see Fig. 10) and $H$ is the final thickness of the splat. They used a 1D heat conduction model to determine $t$ and calculate $S P$. The value of $S P$ depends on the thermal contact resistance $\left(R_{\mathrm{c}}\right)$ between the splat and the substrate, which was assumed to be $10^{-5} \mathrm{~m}^{2} \mathrm{~K} / \mathrm{W}$ in our calculations based 
on previous studies of splat cooling rate in thermal spray processes [32, 33]. In these studies, the thermal contact resistance values were found to depend on the substrate temperature during thermal spraying. The resistance values obtained for substrates that were smooth and held at room temperature in their work were used in our study for calculating SP. Figure 11 shows calculated values of solidification parameter for zinc, aluminum and copper particles. For zinc and aluminum, $S P \leq 0.3$, implying that very little solidification occurred while the droplet was impacting [34]. Droplet would therefore spread out with relatively little break-up and then solidify. Copper droplets had a very high solidification parameter, $S P>2$. Solidification would therefore start immediately after impact, and inhibit spreading of the liquid splat, leading to solidification-induced splashing [34] and splat fragmentation. The central solid core of the splat and the smaller satellite droplets would appear spherical as seen in Fig. 6(c) and 7(c). The SP value greater than 2 for copper particles calculated in this work was also an indication of the extensive splat fragmentation observed. The high melting temperature of copper and the rough porous PE substrate contributed to such splat breakup upon impact.

\section{Adhesion Strength}

All pull tests conducted on the 3-mm-thick polymer samples resulted in the fracture of the porous polyethene substrates before coating detachment. Therefore, the adhesion strength of the coatings was higher than the ultimate fracture strength of the polymer substrates. The samples consistently fractured during the tests at a pull off load of about $3.2 \pm 0.4 \mathrm{MPa}(n=5)$, regardless of the metal used to coat the polymer. This type of fracture led to the formation of a through hole in the sample as shown in Fig. 12. Pull tests were also conducted on thicker $(6 \mathrm{~mm})$ polyethylene substrates coated with zinc, aluminum and copper. The samples fractured again resulting in removal of a

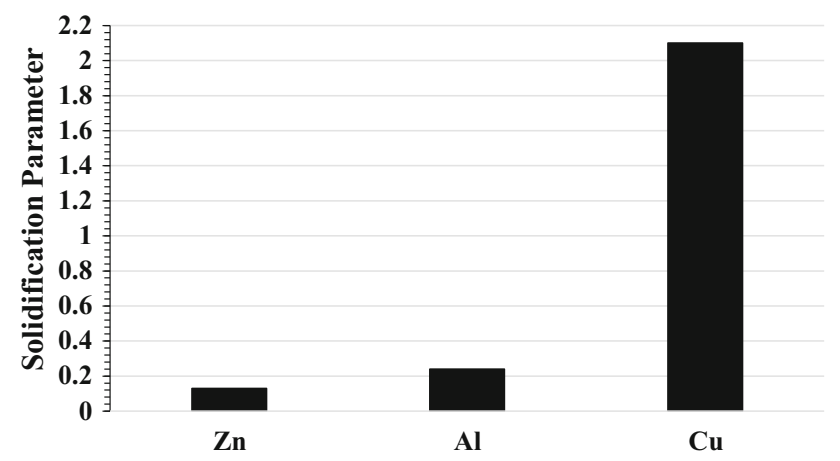

Fig. 11 Solidification parameter values for zinc, aluminum and copper, on porous $\mathrm{PE}$, assuming thermal contact resistance $R_{\mathrm{c}} \sim 10^{-5} \mathrm{~m}^{2} \mathrm{~K} / \mathrm{W}$ portion of the polymer substrate along with the coating material. The pull off load values of the three metallic coatings on the $6 \mathrm{~mm}$ samples are shown in Fig. 13. All pull-off load values measured on the coated porous polyethylene substrates were significantly higher than the adhesion strength of the zinc coating formed on non-porous polyethylene $(0.7 \pm 0.05 \mathrm{MPa}$ for $n=5)$ [27]. The deep penetration of metallic particles into the pores provided excellent mechanical interlocking, which significantly enhanced the bond strength of the coatings. The penetration into the polymeric material can be seen in Fig. 7.

\section{Electrical Resistivity}

Electrical resistivity $(\rho)$ is a material property of the coating and is not a function of the physical dimensions of the coating. The electrical resistivity of the coatings was calculated according to the following equation:

$\rho=\frac{R w t}{l}$,

where $R, w, l$, and $t$ are the electrical resistance, width, length, and thickness of the coating, respectively.

Figure 14 summarizes the electrical resistivity of zinc, aluminum and copper coatings deposited on the porous polyethylene substrates. The electrical resistivity of the coatings was measured at two different coating thicknesses. To compare the electrical resistivity of the coatings with that of bulk metals, metallic foils of similar thickness were chosen and their electrical resistivities were calculated using the four-wire sensing method. The measured values were in good agreement with those provided in previously published studies $[35,36]$. The electrical resistivity of all the three metallic coatings was observed to decrease with the increase in coating thickness. This is due to the considerably smaller cross-sectional area of the thinner coatings layer which is comparatively less effective in conducting current. Additionally, the lower electrical resistivity of thicker coatings could be due to higher compaction in thicker coatings which reduces porosity within the coating layer. Odhiambo et al. [37] discussed the possibility of controlling porosity in plasma-sprayed coatings by spraying multiple layers of coatings on the substrates. The increased volumetric density achieved from these thick coatings reduced the chances of defect propagation. The electrical resistivity of the bulk metals was found to be an order of magnitude lower than the coatings formed through the thermal spray process. This could largely be due to the oxidation of metallic particles in air during thermal spray and the associated porosity in the coatings [38-40]. Similarly, Ashrafizadeh et al. found that the electrical resistivity of flame-sprayed $\mathrm{Al}-12 \mathrm{Si}$ coatings on polyurethane was about three orders of magnitude 
Fig. 12 Fractured adhesion test sample of thickness $3 \mathrm{~mm}$

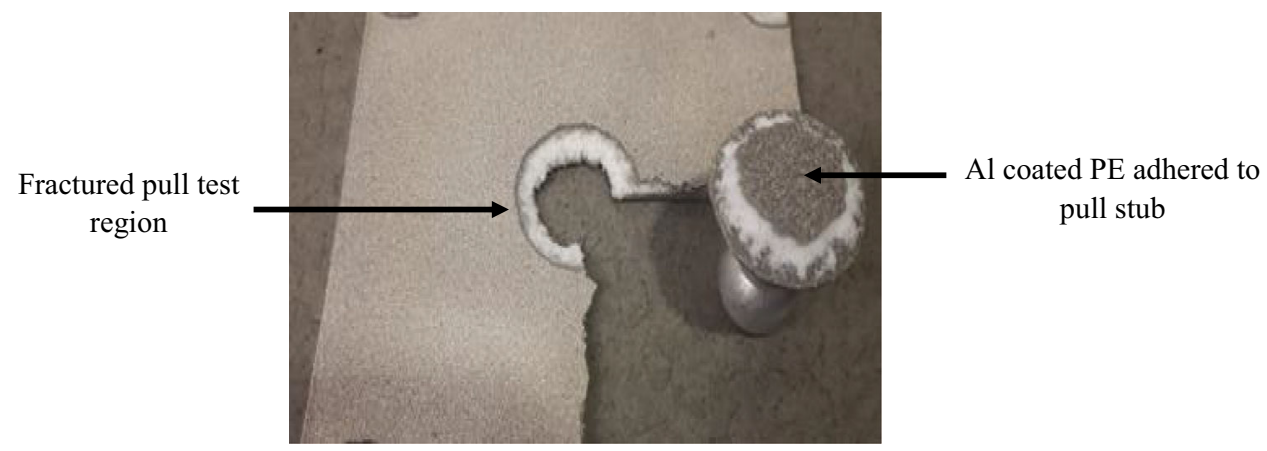

Conclusions

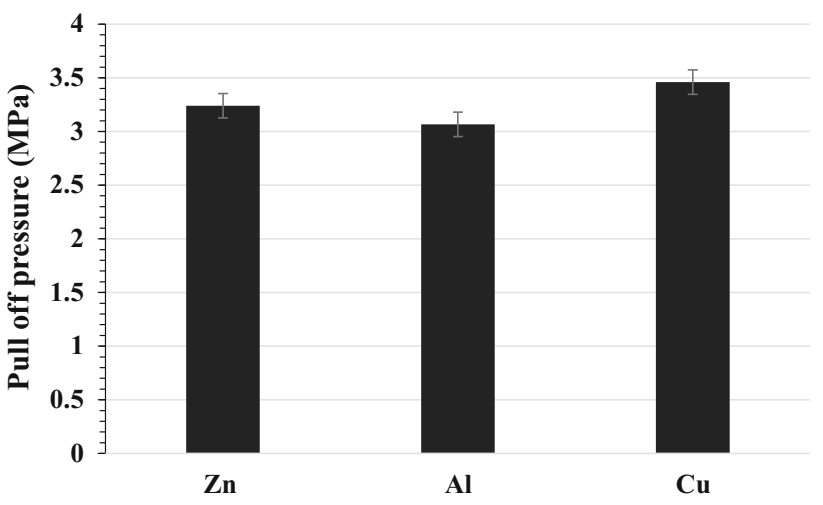

Fig. 13 Pull off loads of zinc, aluminum and copper coated porous polyethylene substrates of thickness $6 \mathrm{~mm}$

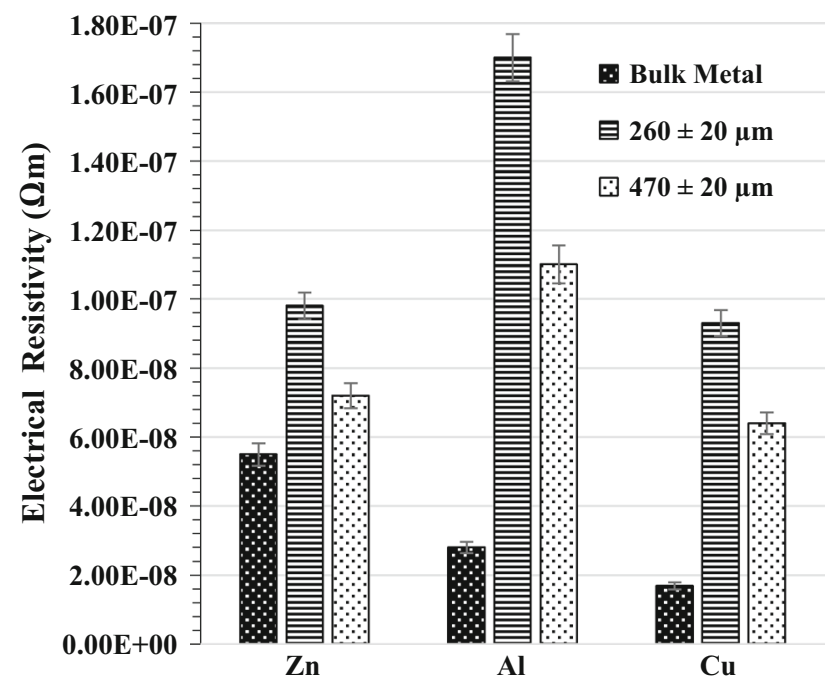

Fig. 14 Electrical resistivity of the coatings $(n=4)$

higher than that of bulk Al-12Si due to the presence of oxides and porosity within the coatings. In general, aluminum and copper coatings possess comparatively higher electrical resistivity than zinc due to their greater affinity towards oxygen [41]. As a result, the difference between the electrical resistivity of the coatings and the bulk metals was found to be the lowest for zinc.
Dense metallic coatings were deposited on porous polyethylene with $70 \mu \mathrm{m}$ average pore size, using an electric wire-arc spray system. Zinc, aluminum and copper coatings were all observed to penetrate deep into the pores, creating excellent mechanical bond with the substrates. The bond strength of all three metallic coatings was found to be higher than the ultimate fracture strength of the porous polymer which fractured before the coating detached during pull tests. The coating adhesion strength of all the three metals on the porous polyethylene samples was found to be significantly higher than the coatings deposited on non-porous polyethylene substrates. Copper spray droplets, which were much smaller than pores on the substrate surface, were mostly observed to penetrate pores. They experienced rapid solidification on impact, which restricted splat spreading. Zinc and aluminum splats were observed to spread to a comparatively greater extent and adhere to both porous and non-porous regions. Therefore, by increasing the void volume or the size of the pores, an even lighter metal-polymer composite material can be fabricated which has tremendous potential to develop cooling solutions for electronic equipment.

Acknowledgments The authors would like to acknowledge the financial support for this work from Natural Science and Engineering Research Council Green Surface Engineering for Advanced Manufacturing (Green-SEAM) Strategic Network. We express gratitude to Dr. Larry Pershin for his guidance and insight throughout this study.

Conflict of interest The authors of this work declare that they have no conflict of interests regarding the publication of this paper.

\section{References}

1. B. Ellis and R. Smith, Polymers: A Property Database, 2nd ed., CRC Press, Boca Raton, 2009

2. C. Feng, S. Ygeswaran, M. Gibbons, and S. Chandra, Analytical heat conduction model of annular composite fins, in Canadian Society for Mechanical Engineering (CSME) International Congress, 2018. 
3. C. Feng, M. Gibbons, and S. Chandra, Fabrication of Composite Heat Sinks Consisting of a Thin Metallic Skin and a Polymer Core Using Wire-Arc Spraying, J. Therm. Spray Tech., 2019, 28, p 974-985.

4. C. Fu, Q. Li, J. Lu, S. Mateti, Q. Cai, X. Zeng, G. Du, R. Sun, Y. Chen, J. Xu, and C.P. Wong, Improving Thermal Conductivity of Polymer Composites by Reducing Interfacial Thermal Resistance Between Boron Nitride Nanotubes, Compos. Sci. Technol., 2018, 165, p 322-330.

5. Y. Agari and T. Uno, Thermal Conductivity of Polymer Filled with Carbon Materials: Effect of Conductive Particle Chains on Thermal Conductivity, J. Appl. Polym. Sci., 1985, 30(5), p 2225-2235.

6. J.G. Drobny, 4-Processing methods applicable to thermoplastic elastomers BT, in Handbook of thermoplastic elastomers (2nd edition). Plastics Design Library, 2014.

7. R.J. Talib, S. Saad, M.R.M. Toff, and H. Hashim, Thermal Spray Coating Technology_A Review, Solid State Sc. Tech., 2003, 11, p 109-117.

8. A. Moign, A. Vardelle, J.G. Legoux, and N.J. Themelis, LCA Comparison of Electroplating and Other Thermal Spray Processes, in Proceedings of the International Thermal Spray Conference, 2009.

9. A.N. Lombardi, L.C. Casteletti, and G.E. Totten, Thermal Spray Technologies: An Overview, Encyclopedia of Tribology. J. Wang and Y.W. Chung, Eds., Springer, Boston, 2013

10. J.G. Cevallos, A.E. Bergles, A. Bar-Cohen, P. Rodgers, and S.K. Gupta, Heat Transfer Engineering Polymer Heat ExchangersHistory, Opportunities, and Challenges Polymer Heat Exchangers-History, Opportunities, and Challenges, Heat Transf. Eng., 2012, 33(12), p 1075-1093.

11. K.H. Su, C.Y. Su, C.T. Cho, C.H. Lin, G.F. Jhou, and C.C. Chang, Development of Thermally Conductive Polyurethane Composite by Low Filler Loading of Spherical BN/PMMA Composite Powder, Sci. Rep., 2019, 9(1), p 1-8.

12. R. Raman, S. Mantell, J. Davidson, C. Wu, and G. Jorgensen, A Review of Polymer Materials for Solar Water Heating Systems, $J$. Sol. Energy Eng. Trans. ASME, 2000, 122(2), p 49-55.

13. I. Krásný, I. Astrouski, and M. Raudenský, Polymeric Hollow Fiber Heat Exchanger as an Automotive Radiator, Appl. Thermal Eng., 2016, 108, p 95-105.

14. J. Song, T. Li, L. Wright-Contreras, and A.W.K. Law, A Review of the Current Status of Small-Scale Seawater Reverse Osmosis Desalination, Water Int., 2017, 42(5), p 618-631.

15. R. Trojanowski, T. Butcher, M. Worek, and G. Wei, Polymer Heat Exchanger Design for Condensing Boiler Applications, Appl. Therm. Eng., 2016, 103, p 150-158.

16. D. Borba Marchetto, D. Carneiro Moreira, and G. Ribatski, A Review on Polymer Heat Sinks for Electronic Cooling Applications, 2019.

17. A. Tessema, D. Zhao, J. Moll, S. Xu, R. Yang, C. Li, S.K. Kumar, and A. Kidane, Effect of Filler Loading, Geometry, Dispersion and Temperature on Thermal Conductivity of Polymer Nanocomposites, Polym. Test., 2017, 57, p 101-106.

18. H. Ashrafizadeh, P. Mertiny, and A. McDonald, Determination of Temperature Distribution within Polyurethane Substrates during Deposition of Flame-Sprayed Aluminum-12Silicon Coatings using Green's Function Modeling and Experiments, Surf. Coat. Tech., 2014, 259, p 625-636.

19. A. Ganesan, M. Yamada, and M. Fukumoto, Cold Spray Coating Deposition Mechanism on the Thermoplastic and Thermosetting Polymer Substrates, J. Therm. Spray Technol., 2013, 22(8), p 1275-1282.
20. H. Che, X. Chu, P. Vo, and S. Yue, Metallization of Various Polymers by Cold Spray, J. Therm. Spray Technol., 2018, 27, p 169-178.

21. M.J. Vucko, P.C. King, A.J. Poole, C. Carl, M.Z. Jahedi, and R. de Nys, Cold Spray Metal Embedment: An Innovative Antifouling Technology, Biofouling, J. Bioadhesion Biofilm Res., 2012, 28(3), p 239-248.

22. V. Pershin, M. Lufitha, S. Chandra, and J. Mostaghimi, Effect of Substrate Temperature on Adhesion Strength of Plasma-Sprayed Nickel Coatings, J. Therm. Spray Technol., 2003, 12, p 370-376.

23. A. Rezzoug, S. Abdi, A. Kaci, and M. Yandouzi, Thermal Spray Metallisation of Carbon Fibre Reinforced Polymer Composites: Effect of Top Surface Modification on Coating Adhesion and Mechanical Properties, Surf. Coatings Technol., 2018, 333, p 13-23.

24. W. Huang, X. Fan, Y. Zhao, X. Zhou, X. Meng, Y. Wang, B. Zou, X. Cao, and Z. Wang, Fabrication of Thermal Barrier Coatings onto Polyimide Matrix Composites via Air Plasma Spray Process, Surf. Coatings Technol., 2012, 207, p 421-429.

25. H. Ashrafizadeh, A. McDonald, and P. Mertiny, Deposition of Electrically Conductive Coatings on Castable Polyurethane Elastomers by the Flame Spraying Process, J. Therm. Spray Technol., 2016, 25, p 419-430.

26. B. Anand, Thermal Spray Deposition of Metals on Polymer Substrates, M.A.Sc. Thesis, University of Toronto, 2019.

27. S. Devaraj, B. Anand, M. Gibbons, A. McDonald, and S. Chandra, Thermal Spray Deposition of Aluminum and Zinc Coatings on Thermoplastics, Surf. Coatings Technol., 2020, 399, p 126114.

28. S. Khameneh Asl and M. Heydarzadeh Sohi, Effect of GritBlasting Parameters on the Surface Roughness and Adhesion Strength of Sprayed Coating, Surf. Interface Anal., 2010, 42(67), p 551-554.

29. K. Alamara, S. Saber-Samandari, and C.C. Berndt, Splat Taxonomy of Polymeric Thermal Spray Coating, Surf. Coatings Technol., 2011, 205, p 5028-5034.

30. A. McDonald, S. Chandra, and C. Moreau, Photographing Impact of Plasma-Sprayed Particles on Rough Substrates, J. Mater. Sci., 2008, 43, p 4631-4643.

31. R. Dhiman, A. McDonald, and S. Chandra, Predicting Splat Morphology in a Thermal Spray Process, Surf. Coat. Technol., 2007, 201(18), p 7789-8801.

32. A. McDonald, C. Moreau, and S. Chandra, Thermal Contact Resistance Between Plasma-Sprayed Particles and Flat Surfaces, Int. J. Heat Mass Transf., 2007, 50(9-10), p 1737-1749.

33. Y. Heichal and S. Chandra, Predicting Thermal Contact Resistance Between Molten Metal Droplets and a Solid Surface, $J$. Heat Transf., 2005, 127(11), p 1269-1275.

34. S. Chandra and P. Fauchais, Formation of Solid Splats During Thermal Spray Deposition, J. Therm. Spray Technol., 2009, 18, p $148-180$.

35. W. Callister, Materials Science and Engineering. An Introduction, 5th ed., Wiley, New York, 2000

36. K. Bobzin, M. Öte, M.A. Knoch, X. Liao, C. Hopmann, and P. Ochotta, Electrical resistivity of wire arc sprayed $\mathrm{Zn}$ and $\mathrm{Cu}$ coatings for in-mold-metal-spraying, in IOP Conference Series: Materials Science and Engineering, 2018.

37. J.G. Odhiambo, W.G. Li, Y.T. Zhao, and C.L. Li, Porosity and Its Significance in Plasma-Sprayed Coatings, Coatings, 2019, 9(7), p 460-479.

38. G.D. Lunn, M.A. Riley, and D.G. McCartney, A Study of Wire Breakup and In-Flight Particle Behavior During Wire Flame Spraying of Aluminum, J. Therm. Spray Technol., 2017, 26, p 1947-1958. 
39. O. Sharifahmadian, H.R. Salimijazi, M.H. Fathi, J. Mostaghimi, and L. Pershin, Study of the Antibacterial Behavior of Wire Arc Sprayed Copper Coatings, J. Therm. Spray Technol., 2013, 22, p 371-379.

40. E. Abedi Esfahani, H. Salimijazi, M.A. Golozar, J. Mostaghimi, and L. Pershin, Study of Corrosion Behavior of Arc Sprayed Aluminum Coating on Mild Steel, J. Therm. Spray Technol., 2012, 21, p 1195-1202.
41. V.A. Greenhut, J.D. Idol, R.L. Lehman, D.J. Strange, S.H. Kosmatka, B.C. Goswami, W. Wang, R.A. Ridilla, M.B. Buczek, and W.F. Fischer, Materials, The CRC Handbook of Mechanical Engineering, 2nd Edition, 2004.

Publisher's Note Springer Nature remains neutral with regard to jurisdictional claims in published maps and institutional affiliations. 